\title{
MicroscopyPioneers
}

\section{Pioneers in Optics: Giovanni Borelli}

\section{Eric Clark}

From the website Molecular Expressions created by the late Michael Davidson and now maintained by Eric Clark, National Magnetic Field Laboratory, Florida State University, Tallahassee, FL 32306

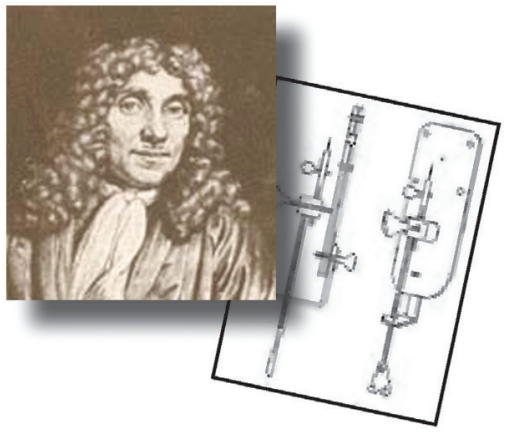

eclark@magnet.fsu.edu

\section{Giovanni Borelli \\ (1608-1679)}

Giovanni Francesco Antonio Alfonso, who later changed his surname to Borelli, was born in Naples, Italy, on January 28, 1608, the son of a Spanish infantryman. He was a great mathematician and physicist, as well as an adept microscopist, and was dedicated to preserving and advancing the Galilean tradition of studying nature. He is most renowned for his studies in physiology.

Borelli was a professor of mathematics at Messina beginning in 1649 but took another

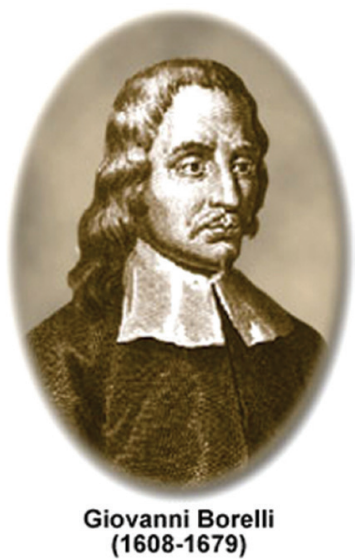
teaching position in Pisa in 1656. Eleven years later he returned to Messina but was compelled to retire in 1674 to Rome, where he lived under the protection of Christina, Queen of Sweden. Throughout his lifetime Borelli carefully studied a variety of topics, but he is particularly noted for his microscopic investigations of red blood cells and his accurate observation of the regularity of stomatal movements in plants.

Intrigued by astronomy, Borelli wrote numerous works on the topic, including a paper in 1666 that deliberated the effect of attraction on the satellites of Jupiter. Additionally, in a letter published in 1665 under the pseudonym Pier Maria Mutoli, Borelli was the first to suggest that comets travel in a parabolic path.

Borelli's most famous work, however, was On the Movement of Animals, but he did not live to see it in print. The paper, which was published posthumously in two parts between 1680 and 1681, often garners Borelli the title father of biomechanics. His physiological study was based on solid mechanical principles, and the work included muscle analysis and a mathematical illustration of movements, such as running and jumping. In the paper, Borelli also attempted to clarify the reason for muscle fatigue, explain organ secretion, and hypothesize on the concept of pain.

Extremely inventive, Borelli is also often remembered by scuba diving enthusiasts for his drawings of a closed circuit "rebreather." His illustrations depict a giant bag utilizing chemical components, which he suggested should allow the air to be breathed again by a submerged diver. Although the device was apparently never made, his design was the first to visualize a diver as a free-swimming "frogman."

Borelli died in Rome on December 31, 1679, but his impressive body of original work helped inspire a great number of future scientists, microscopists, and inventors. The highest honor bestowed by the American Society of Biomechanics is the Giovanni Borelli Award, which is given annually to an investigator who has conducted exemplary research in biomechanics.

MT

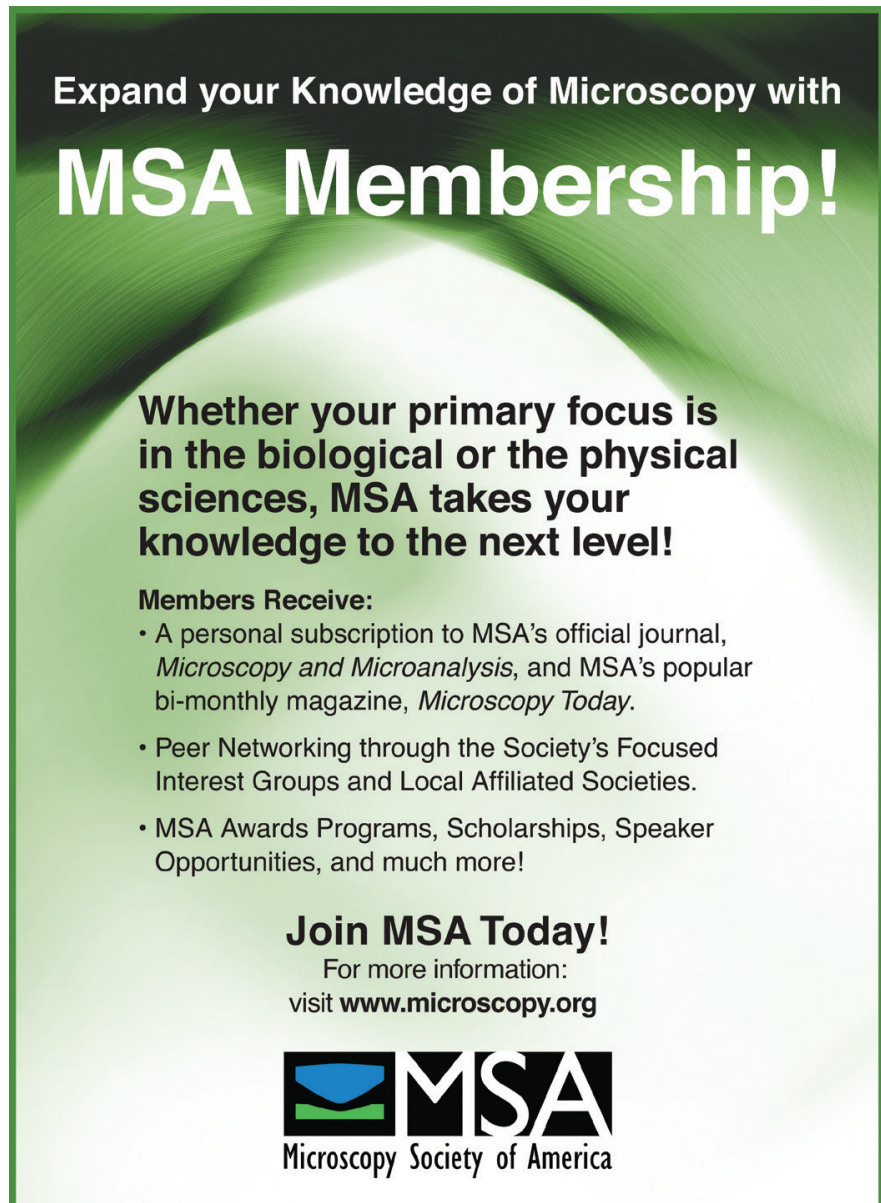

